\title{
Effect of Aerobic Exercise on Thyroid Hormones and Quality of Life in Obese Postmenopausal Women
}

\author{
Mehrdad Fathi (PhD) \\ Department of Sport Physiology, \\ Faculty of Physical Education and \\ Sports Sciences, Ferdowsi University \\ of Mashhad, Mashhad, Iran \\ Mohammad Mosaferi Ziaaldini \\ (PhD) \\ Department of Sport Physiology, \\ Faculty of Physical Education and \\ Sports Sciences, Ferdowsi University \\ of Mashhad, Mashhad, Iran \\ Somaye Khairabadi $(\mathbf{P h D})$ \\ Department of Sport Physiology, \\ Faculty of Physical Education and \\ Sports Sciences, Ferdowsi University \\ of Mashhad, Mashhad, Iran \\ Keyvan Hejazi (PhD) \\ Department of Sport Physiology, \\ Faculty of Physical Education and \\ Sports Sciences, Toos Institute of \\ Higher Education, Mashhad, Iran \\ Corresponding author: Mehrdad \\ Fathi \\ Email: mfathei@um.ac.ir \\ Tel:+989151253513 \\ Address: Department of Exercise \\ Physiology, Faculty of Physical \\ Education and Sport Sciences, \\ Ferdowsi University of Mashhad, \\ Mashhad, Iran \\ Received: 11 Apr 2018 \\ Revised: 02 Jul 2018 \\ Accepted: 22 Jul 2018
}

\begin{abstract}
Background and objectives: Studies have shown that exercise can affect hormone secretion and some metabolic and endocrine functions. The aim of this study was to assess the effect of eight weeks of aerobic training on thyroid hormones and quality of life in obese postmenopausal women.

Methods: In this semi-experimental study, 21 obese (body mass index $>30 \mathrm{Kg} / \mathrm{m}^{2}$ ) women aged between 35 and 45 were randomly divided into an experimental $(n=10)$ group and a control group $(\mathrm{n}=11)$. The subjects in the experimental group performed $30-60$ minutes of aerobic exercise at $65-75 \%$ of maximum heart rate, three times a week, for eight weeks. Level of thyroid hormones and quality of life subscales were compared within and between the groups. Statistical analysis was performed at significance level of 0.05 .

Results: After the eight-week exercise program, thyroxine, triiodothyronine and thyrotropin releasing hormone levels increased significantly, and thyroid releasing hormone level decreased significantly $(\mathrm{P}=0.001)$. The exercise program also had significantly positive effects on quality of life and its occupational, sexual and emotional subscales in obese postmenopausal women.
\end{abstract}

Conclusion: Aerobic exercise causes a significant increase in levels of thyroxine, triiodothyronine and thyrotropin releasing hormone and some subscales of quality of life. It also causes a significant decrease in thyroid releasing hormone level, which indicates the effect of exercise on hormone secretion.

KEYWORIDS: Thyroid hormones, Obese, Quality of life, Aerobic training. 


\section{INTRODUCTION}

Obesity negatively affects humans health and is associated with numerous health problems, including cardiovascular disease, diabetes, hypertension, digestive disorders and respiratory disease (1). A series of hormonal disorders (2) as well as genetic, behavioral, environmental, physiological, social, cultural and nutritional factors (3) can contribute to obesity. Obesity can also influence endocrine functions by affecting the hypothalamicpituitary-thyroid axis (2). Hypothalamus secretes thyrotropin releasing hormone (TRH) that stimulates secretion of thyroid stimulating hormone (TSH) from the pituitary gland (4), which itself increases the secretion of thyroid hormones (5). Thyroxin (T4) and triiodothyronine (T3) are two of the most important hormones secreted from the thyroid gland, which affect almost all tissues of the body (6).

Physical activity has a regulating role on thyroid function, and research has shown that adequate activity can prevent or reduce the burden of thyroid-related diseases and other hormonal disorders (7). In this regard, Onsori et al. examined the effect of thrice weekly 60minute aerobic exercise sessions for 12 weeks on level of thyroid hormone in 30 inactive women, and concluded that plasma levels of TSH and thyroid hormones do not change significantly at the end of the exercise period (8). Beyleroglu et al. examined the effect of shuttle run test on 14 hockey players and found no significant difference between serum TSH levels and thyroid hormones (9). In the mentioned study, FT3 and TSH levels decreased significantly one hour after exercise, while FT4 and cortisol levels increased slightly. In a study by Ciloglu et al., acute exercise at different intensities $(45 \%, 70 \%$ and $90 \%$ of maximum heart rate) increased $\mathrm{T} 4$, FT4 and TSH levels and decreased T3 and FT3 levels in men (10).

It is well understood that menopause has a dramatic effect on quality of life of women. Regular physical activity and exercise can improve mental health and self-esteem, thus improving the quality of life and life satisfaction (11, 12). Moreover, moderate intensity exercise have positive effects on the mental health and quality of life of postmenopausal women (13). However, the majority of middle-aged women do not have enough physical activity to produce such effects (14). The effect of exercise on thyroid hormone responses and the quality of life of postmenopausal women have been studied extensively, but the results of these studies are contradictory. In order to clarify this issue, we aimed to evaluate the effect of an eight-week continuous aerobic exercise program on the thyroid hormones and quality of life of postmenopausal women.

\section{MATERIAL AND METHODS}

This was a quasi-experimental controlled study with a pretest and posttest design. Study population included 21 middle age (35-45 years) and healthy women living in Mashhad (Iran), with body mass index (BMI) of $30-35 \mathrm{Kg} / \mathrm{m}^{2}$. The subjects were selected through available and targeted sampling. In the first stage, the subjects became familiar with the nature and purpose of the study. Inclusion criteria were as follows: overall good health based on the general practice physical activity questionnaire (GPPAQ) and no history of drug use, smoking and participation in any exercise program for at least two months prior to the study. The subjects voluntarily participated in the study and signed a consent form. After randomly assigning the subjects into an experimental group $(n=10)$ and a control group $(\mathrm{n}=11)$, we determined the level of physical activity for each individual by using the Kaiser physical activity survey (15). The

questionnaire assesses the habits and patterns of physical activity, especially in women. In this questionnaire, questions are grouped into four sections: 1) "Household and Family Care Activities"; 2) "Occupational Activities"; 3) "Active Living Habits"; and 4) "Participation in Sports and Exercise" (15).

Quality of life was evaluated using the Utian Quality of Life (UQOL) scale, which is the most commonly used tool for assessing quality of life (16). The scale has 23 items in occupational, health, emotional and sexual subscales.

Height of the subjects was measured with a Seca measuring tape (made in Germany) with a sensitivity of $5 \mathrm{~mm}$. Hip and waist circumference was measured by a tape (Mabis / Japan) with a sensitivity of $5 \mathrm{~mm}$. Weight of the subjects was measured by a Digital Beurer Scale (PS06-PS07 model). Then, for measuring body fat percentage using calipers of Lafit type, two points (triceps of the arm 
and leg) were used. Body fat percentage was calculated using the Luman-Slater formula $(0.735 \times$ (sum of two points of three parts of the arm and legs in millimeters) +1 ). BMI was calculated by dividing weight in kilograms by the square of height in meters. Waist to hip ratio was calculated by measuring waist circumference with a meter strip at the lowest point (between the lower end of the chest and navel) in $\mathrm{cm}$ and the hip circumference (in the widest area, on the cap) in $\mathrm{cm}$. The subjects were instructed not to eat or drink for at least four hours before testing. The Naughton treadmill protocol was used to estimate the maximum oxygen consumption using the following equation: Maximum oxygen consumption $(\mathrm{ml} / \mathrm{kg} / \mathrm{min})=1.61$ (time per $\min )+3.6(17)$.

A qualified laboratory technician performed blood sampling in two stages: 24 hours before the first exercise session and 48 hours after the last exercise session (18). Samples were taken from the left hand vestibule of each subject in sitting position and at rest, between 8 and 12:00 A.M in the laboratory. To determine the level of serum thyroid hormones, thyroid hormones levels were determined by ELISA method using RADIM kits (Italy).

The exercise program consisted of 45 to 60 minutes of aerobic exercise, which was performed three times a week for eight weeks. The exercise protocol included general warm up for 10 minutes (walking, slow running, stretching and jumping) and aerobic exercise for $45-60$ minutes at $65-75 \%$ of maximal heart rate. Duration of each exercise session increased gradually from 30 minutes to 60 minutes by the end of the course. Exercise intensity was controlled by POLAR heart monitor (Finland) (19). At the end of each session, the subjects cooled down for 10 minutes by slow running, walking and stretching movements.

Collected data were analyzed by SPSS 16.0 software. After confirming the normal distribution of data (by the KolmogorovSmirnov test) and homogeneity of variances (by the Levene's test), within and between group comparison of means was made using repeated measures ANOVA. P-values less than 0.05 were considered statistically significant.

\section{RESULTS}

Table 1 shows the characteristics of the experimental and control groups. The eightweek aerobic exercise program resulted in a significant increase in $\mathrm{T} 4 \quad(\mathrm{P}=0.001), \mathrm{T} 3$ $(\mathrm{P}=0.001)$ and TRH $(\mathrm{P}=0.001)$ levels. However, TSH decreased significantly $(\mathrm{P}=0.001)$ in obese women following the exercise program (Table 2). The quality of life subscales (occupation, emotion and sexual) and quality of life of middle-aged menopausal women improved significantly after the program $(\mathrm{P}<0.05)$. Moreover, level of $\mathrm{T} 4, \mathrm{~T} 3$, TSH and TRH differed significantly between the two groups $(\mathrm{P}<0.001)$. The quality of life and the subscale of emotion differed significantly between the two study groups (Table 3).

Table 1- Characteristics of the subjects in the two study groups

\begin{tabular}{ccccc}
\hline Groups & \multicolumn{4}{c}{ Variations (M \pm SD) } \\
\cline { 2 - 5 } & Age (Years) & Height $(\mathbf{c m})$ & Weight $(\mathbf{K g})$ & BMI $\left(\mathrm{Kg} / \mathbf{m}^{2}\right)$ \\
Experimental $(\mathrm{n}=\mathbf{1 0})$ & $\mathbf{3 7 . 8 0} \pm \mathbf{3 . 6 4}$ & $\mathbf{1 6 3 . 9 0} \pm \mathbf{3 . 2 4}$ & $\mathbf{8 3 . 1 0} \pm \mathbf{5 . 3 8}$ & $\mathbf{3 0 . 9 6} \pm \mathbf{1 . 3 7}$ \\
Control & $\mathbf{4 0 . 0 0} \pm \mathbf{3 . 1 3}$ & $\mathbf{1 5 8 . 7 3} \pm \mathbf{6 . 0 6}$ & $\mathbf{8 4 . 7 3} \pm 7.77$ & $\mathbf{3 3 . 5 8} \pm \mathbf{1 . 7 3}$ \\
$(\mathrm{n}=\mathbf{1 1})$ & & & & \\
\hline
\end{tabular}

Table 2- Inter- and intra-group comparison of mean hormone levels before and after the exercise program

\begin{tabular}{|c|c|c|c|c|c|c|c|}
\hline \multirow[t]{3}{*}{ Variables } & \multirow[t]{3}{*}{ Group } & \multicolumn{2}{|c|}{ Stages } & \multicolumn{4}{|c|}{ Variations } \\
\hline & & \multirow[t]{2}{*}{$\begin{array}{c}\text { Pre-test Mean } \\
\pm \text { SD }\end{array}$} & \multirow[t]{2}{*}{$\begin{array}{c}\text { Post-test } \\
\text { Mean } \pm \text { SD }\end{array}$} & \multicolumn{2}{|c|}{$\begin{array}{l}\text { Within } \\
\text { Group }\end{array}$} & \multicolumn{2}{|c|}{$\begin{array}{l}\text { Between } \\
\text { group }\end{array}$} \\
\hline & & & & $\mathbf{t}$ & P-Value & $\mathbf{t}$ & P-Value \\
\hline \multirow{2}{*}{$\begin{array}{c}\mathrm{T} 4 \\
(\mathrm{mg} / \mathrm{L})\end{array}$} & Exercise & $7.16 \pm 0.43$ & $8.17 \pm 0.75$ & 6.97 & $0.01 \dagger$ & 7.11 & $0.01 \dagger$ \\
\hline & Control & $8.12 \pm 0.78$ & $8.06 \pm 0.80$ & 1.50 & 0.16 & & \\
\hline \multirow[t]{2}{*}{ T3 (ng/dL) } & Exercise & $1.44 \pm 0.32$ & $1.9 \pm 0.16$ & 7.04 & $0.01 \dagger$ & 6.02 & $0.01 \dagger$ \\
\hline & Control & $1.42 \pm 0.27$ & $1.44 \pm 0.27$ & 0.61 & 0.55 & & \\
\hline \multirow[t]{2}{*}{ TSH $(\mu \mathrm{l} / \mathrm{mL})$} & Exercise & $2.71 \pm 0.62$ & $1.91 \pm 0.47$ & 5.42 & $0.01 \dagger$ & 4.94 & $0.01 \dagger$ \\
\hline & Control & $2.67 \pm 0.62$ & $2.63 \pm 0.63$ & 0.93 & 0.37 & & \\
\hline \multirow[t]{2}{*}{ TRH (\%) } & Exercise & $27.60 \pm 1.71$ & $31.20 \pm 1.93$ & 9.00 & $0.01 \dagger$ & 6.60 & $0.01 \dagger$ \\
\hline & Control & $28.50 \pm 1.58$ & $28.60 \pm 2.06$ & 0.28 & 0.78 & & \\
\hline
\end{tabular}


Table 3- Inter- and intra-group comparison of quality of life and its subscales before and after the exercise program

\begin{tabular}{|c|c|c|c|c|c|c|c|}
\hline \multirow{3}{*}{ ariables } & \multirow{3}{*}{ Group } & \multicolumn{2}{|c|}{ Stages } & \multicolumn{4}{|c|}{ Variations } \\
\hline & & \multirow{2}{*}{$\begin{array}{c}\text { Pre-test Mean } \\
\pm \text { SD }\end{array}$} & \multirow{2}{*}{$\begin{array}{c}\text { Post-test } \\
\text { Mean } \pm \text { SD }\end{array}$} & \multicolumn{2}{|c|}{$\begin{array}{l}\text { Within } \\
\text { group }\end{array}$} & \multicolumn{2}{|c|}{$\begin{array}{c}\text { Between } \\
\text { group }\end{array}$} \\
\hline & & & & $t$ & P-Value & $\mathbf{t}$ & P-Value \\
\hline \multirow{2}{*}{ Quality of life } & Exercise & $2.50 \pm 4.5$ & $3.03 \pm 0.34$ & -3.82 & $0.04 \dagger$ & \multirow{2}{*}{-3.08} & \multirow{2}{*}{$0.006 \dagger$} \\
\hline & Control & $2.62 \pm 0.24$ & $2.58 \pm 0.39$ & 0.30 & 0.76 & & \\
\hline \multirow{2}{*}{ Occupational subscale } & Exercise & $2.50 \pm 0.38$ & $2.68 \pm 0.35$ & -2.68 & $0.02 \dagger$ & \multirow{2}{*}{-1.94} & \multirow{2}{*}{0.06} \\
\hline & Control & $2.50 \pm 0.27$ & $2.49 \pm 0.42$ & 0.16 & 0.87 & & \\
\hline \multirow{2}{*}{ Health subscale } & Exercise & $2.91 \pm 0.25$ & $2.95 \pm 0.57$ & -0.21 & 0.83 & \multirow{2}{*}{-0.9} & \multirow{2}{*}{0.37} \\
\hline & Control & $2.92 \pm 0.34$ & $2.79 \pm 0.41$ & 1.31 & 0.21 & & \\
\hline \multirow{2}{*}{ Emotional subscale } & Exercise & $2.99 \pm 0.27$ & $3.44 \pm 0.26$ & -4.61 & $0.01 \dagger$ & \multirow{2}{*}{-4.29} & \multirow{2}{*}{$0.001 \dagger$} \\
\hline & Control & $3.25 \pm 0.17$ & $3.20 \pm 0.31$ & 0.75 & 0.46 & & \\
\hline \multirow{2}{*}{ Sexual subscale } & Exercise & $3.38 \pm 0.16$ & $3.56 \pm 0.28$ & -2.67 & $0.02 \dagger$ & \multirow{2}{*}{-1.88} & \multirow{2}{*}{0.07} \\
\hline & Control & $3.32 \pm 0.20$ & $3.33 \pm 0.36$ & -0.29 & 0.77 & & \\
\hline
\end{tabular}

$\dagger$ Statistically significant difference $(\mathbf{P}<0.05)$

\section{DISCUSSION}

The purpose of this study was to investigate the effect of eight weeks of aerobic exercise on the concentration of thyroid hormones in obese middle-aged women. Based on the results obtained from this study, the aerobic exercise program resulted in a significant increase in the levels of thyroxin, T3 and TRH. These results are consistent with the findings of Ciloglu et al. (10) and Rahimi et al. (20) but inconsistent with the findings of Onsori et al. (8). In a study on 60 male athletes, Ciloglu et al. evaluated the effects of exercise at different intensities on a cycle ergometer and reported that exercise at $70 \%$ of maximum heart rate increases thyroid hormone levels. They also found that T4, FT4 and TSH increase and T3 and FT3 decrease significantly after exercise at intensity of $90 \%$ of maximum heart rate (10). However, levels of TSH, T3 and T4 did not change significantly in a study on 30 young men who performed eight weeks of resistance exercise, three sessions per week with an intensity of 20 to $55 \%$ (20). Onsori et al. examined the effect of 12 weeks of aerobic exercise (60 minutes), three sessions a week, on thyroid hormones of 30 inactive women, and showed that plasma levels of T3 and T4 do not change significantly (8). The thyroid hormones activate nuclear transcription of a large number of genes (21), thus increasing the amount of enzymes, structural proteins, transferring proteins and other substances in virtually all cells of the body (21). A large portion of the T4 secreted by the thyroid gland is converted to T3. Before acting as a transcription factor, iodine is taken from T4 to form T3 (22). One of the enzymes that elevates thyroid hormone response is sodiumpotassium adenosine triphosphatase, which increases the amount of both sodium and potassium in the cell membrane of some tissues (23). Since this process consumes energy and increases the amount of heat generated in the body, it could be considered as one of the mechanisms through which the thyroid hormones increase the body metabolism (24). In fact, the thyroid hormones increases the permeability of cell membrane to sodium, thereby further activating the sodium pump and further increasing the heat generation (25). The thyroid hormones have a feedback control on secretion of TSH. In these neurons, T3 inhibits the expression of gene. The increase of serum T3 immediately after exercise is probably caused by an adrenergic stimulus during the exercise. However, exercise at intensity of more than $60 \%$ $\mathrm{VO}_{2} \mathrm{max}$ increases catecholamine levels (26, 27). In our study, the aerobic exercise program significantly reduced TSH level among obese women. This is consistent with the findings of Beyleroglu et al. (9) and Bansal et al. (28) but inconsistent with the findings of Nicoll et al. (29). Production and secretion of the thyroid hormones is regulated by $\mathrm{TSH}$, which is secreted from the pituitary gland. TSH secretion itself increases by TRH, which is produced in the hypothalamus. Thrombocytopenic somatostatin and thyroid hormones reduce the effects of TSH. In fact, the thyroid hormones can lower TRH secretion by affecting the hypothalamus (30). We found that the aerobic exercise program significantly improved quality of life and its subscales in middle-aged menopausal women. 
This is in line with findings of Murtezani et al. (31) and Dixit et al. (32) but inconsistent with results of Nuri et al. (33). Murtezani et al. reported that 25-40 minutes of aerobic exercise with moderate intensity for 10 week significantly improves the quality of life and physical functioning of 62 women with breast cancer (31). Dixit et al. reported that moderate intensity aerobic exercise is a fundamental aspect of improving quality of life of type 2 diabetics with peripheral neuropathy (32). It has believed that physical activity improves cognitive function by promoting social activities in middle-aged people. Participation in more physical activities and in large social groups increases brain stimulation and indirectly reduces symptoms of depression $(34,35)$. Physical exercise is directly involved in emotion regulation initially via release of endorphins, then by reduction of cortisol (stress hormone) level $(35,36)$.

One of the most important benefits of physical activity is its social aspect. During exercise, people inevitably engage with one another, a process called socializing, which is an aspect of quality of life (37). Exercise also improves self-esteem, self-reliance and confidence. The present study had some limitations including dietary divergence, limited number of volunteers and individual differences.

\section{CONCLUSION}

The eight-week aerobic exercise program significantly increases the level of thyroid hormones (T4 and T3) and TRH but significantly reduces the TSH level in obese women. Regular aerobic exercise is recommended for obese women who are exposed to stress since it improves quality of life and helps adjust hormone levels. However, more research is required to reach a definite conclusion in this regard.

\section{ACKNOWLEDGMENTS}

We would like to offer our gratitude to all subjects for participating in the study. This work was supported by a grant (code: 42314) from Ferdowsi University of Mashhad, Iran.

\section{CONFLICT OF INTEREST}

The authors declare that there is no conflict of interest. 


\section{REFFRENCES}

1. Chen Y, Dales R, Tang M, Krewski D. Obesity may increase the incidence of asthma in women but not in men: longitudinal observations from the Canadian National Population Health Surveys. American Journal of Epidemiology. 2002;155(3):191-7.

2. Krotkiewski M. Thyroid hormones in the pathogenesis and treatment of obesity. European journal of pharmacology. 2002;440(2-3):85-98.

3. Organization WH. Obesity: preventing and managing the global epidemic: World Health Organization; 2000.

4. Hall JE. Guyton and Hall textbook of medical physiology e-Book: Elsevier Health Sciences; 2015.

5. Kuehn FS, Lozada MP. Thyroid Hormones: Functions, Related Diseases and Uses: Nova Science Pub Incorporated; 2009.

6. Belza A, Toubro S, Astrup A. The effect of caffeine, green tea and tyrosine on thermogenesis and energy intake. European journal of clinical nutrition. 2009;63(1):57-63.

7. Thompson JK, Jarvie GJ, Lahey BB, Cureton KJ. Exercise and obesity: etiology, physiology, and intervention. Psychological Bulletin. 1982;91(1):55.

8. Onsori M, Galedari M. Effects of 12 weeks aerobic exercise on plasma level of TSH and thyroid hormones in sedentary women. European Journal of Sports and Exercise Science. 2015;4(1):45-9.

9. Beyleroglu M. The effects of maximal aerobic exercise on cortisol and thyroid hormones in male field hockey players. African Journal of Pharmacy and Pharmacology. 2011;5(17):2002-6.

10. Ciloglu F, Peker I, Pehlivan A, Karacabey K, İlhan $\mathrm{N}$, Saygin $\mathrm{O}$, et al. Exercise intensity and its effects on thyroid hormones. Neuroendocrinology letters. 2005;26(6):830-4.

11. Elavsky S. Physical activity and quality of life during menopause: University of Illinois at Urbana-Champaign; 2006.

12. Elavsky S, McAuley E. Lack of perceived sleep improvement after 4-month structured exercise programs. Menopause. 2007;14(3):535-40.

13. Hammar M, Lindgren R. Does physical exercise influence the frequency of postmenopausal hot flushes? Acta obstetricia et gynecologica Scandinavica. 1990;69(5):409-12.

14. Amirian Z, Jalali R, Rigi F, Nadery A, Amirian M, Salehi S. Comparison of the quality of life in patients after coronary artery bypass graft surgery $(C A B G)$ in the rural and urban communities. J Kermanshah Univ Med Sci. 2014;18(4):226-33.

15. Sternfeld B, Ainsworth BE, Quesenberry Jr C. Physical activity patterns in a diverse population of women. Preventive Medicine. 1999;28(3):313-23.

16. Utian WH. Psychosocial and socioeconomic burden of vasomotor symptoms in menopause: a comprehensive review. Health and Quality of Life outcomes. 2005;3(1):47.

17. Acevedo EO, Starks M, Starks MA. Exercise testing and prescription lab manual: Human Kinetics; 2011.

18. Balsam A, Leppo L. Effect of physical training on the metabolism of thyroid hormones in man. Journal of applied physiology. 1975;38(2):212-5.
19. Ghahremani Moghadam M. Effect of aerobic training for 8 weeks on c-reactive protein, uric acid and total bilirubin in sedentary elderly women. The Horizon of Medical Sciences. 2015;21(2):81-9.

20. Rahimi E, Zadeh YM, Boostani MA. The effect of resistance training on thyroid hormones. European Journal of Experimental Biology. 2013;3(2):443-7.

21. Oppenheimer J. Molecular basis of thyroid hormone action: Elsevier; 2012.

22. Wulf A, Wetzel MG, Kebenko M, Kröger M, Harneit $\mathrm{A}$, Merz J, et al. The role of thyroid hormone receptor DNA binding in negative thyroid hormone-mediated gene transcription. Journal of molecular endocrinology. 2008;41(1):25-34.

23. $\mathrm{Wu} \mathrm{Y}$, Koenig RJ. Gene regulation by thyroid hormone. Trends in Endocrinology \& Metabolism. 2000;11(6):207-11.

24. Wrutniak-Cabello C, Casas F, Cabello G. Thyroid hormone action in mitochondria. Journal of molecular endocrinology. 2001;26(1):67-77.

25. Shah M, Quigley R, Baum M. Maturation of proximal straight tubule $\mathrm{NaCl}$ transport: role of thyroid hormone. American Journal of Physiology-Renal Physiology. 2000;278(4):F596-F602.

26. Klein S, Coyle EF, Wolfe RR. Fat metabolism during low-intensity exercise in endurance-trained and untrained men. American Journal of PhysiologyEndocrinology And Metabolism. 1994;267(6):E934-E40.

27. Ahren B, Bengtsson H, Hedner P. Effects of norepinephrine on basal and thyrotropin-stimulated thyroid hormone secretion in the mouse. Endocrinology. 1986;119(3):1058-62.

28. Bansal A, Kaushik A, Singh C, Sharma V, Singh H. The effect of regular physical exercise on the thyroid function of treated hypothyroid patients: An interventional study at a tertiary care center in Bastar region of India. Archives of Medicine and Health Sciences. 2015;3(2):244.

29. Nicoll J. Thyroid hormones, performance, and psychological changes on overtraining in female distance runners: University of Rhode Island; 2014.

30. Sack J, Shafrir Y, Urbach D, Amado O. Thyroidstimulating hormone, prolactin, and growth hormone response to thyrotropin-releasing hormone in treated children with congenital hypothyroidism. Pediatric research. 1985;19(10):1037.

31. Murtezani A, Ibraimi Z, Bakalli A, Krasniqi S, Disha $\mathrm{ED}$, Kurtishi I. The effect of aerobic exercise on quality of life among breast cancer survivors: a randomized controlled trial. Journal of cancer research and therapeutics. 2014;10(3):658.

32. Dixit S, Maiya A, Shastry B. Effect of aerobic exercise on quality of life in population with diabetic peripheral neuropathy in type 2 diabetes: a single blind, randomized controlled trial. Quality of Life Research. 2014;23(5):1629-40.

33. Nuri R, Damirchi A, Rahmani-Nia F, Emami H, Rahnama N. Effect of exercise training on the quality of life in postmenopausal women with breast cancer. Brazilian journal of Biomotricity. 2009;3(4). 
34. Asbury EA, Chandrruangphen $\mathrm{P}$, Collins P. The importance of continued exercise participation in quality of life and psychological well-being in previously inactive postmenopausal women: a pilot study. Menopause. 2006;13(4):561-7.

35. Sadegh S, Fathei M, Hejazi K, Kiani gol M. The Effect of 8 Weeks of Aerobic Training on Adiponectin Levels and Quality of Life in Inactive Middle-Aged Women. Qom Univ Med Sci J . 2016; 10 (9) :1-11
36. McGovern M. The effects of exercise on the brain. Serendip brymawr edu. 2005.

37. Kargarfard M, Dehghani M, Heidari A. Effect of a period of aquatic exercise therapy on the quality of life, anxiety and depression in patients with hemophilia. koomesh. 2011;12(4). 